\title{
The Effect of Revert Addition on Microstructure and Mechanical Properties of K418 Ni-base Superalloy
}

\author{
Xiaojuan YANG ${ }^{1}$, Xiaowen WANG ${ }^{1}$, Juanjuan $\mathrm{LI}^{1}$ and ${ }^{*}$ Shengzhong KOU ${ }^{1, a}$ \\ Jianbin $\mathrm{ZHANG}^{1, \mathrm{~b}}$
}

\begin{abstract}
${ }^{1}$ State Key Laboratory of Non-ferrous Metal Alloys and Processing of Ministry of Education, Lanzhou University of Technology, Lanzhou 730050, China
\end{abstract}

aemail: kousz@lut.cn, bjbzhangjb@hotmail.com (*Corresponding author)

\begin{abstract}
Keywords: Ni-based superalloy, microstructure, tension, revert addition
\end{abstract}
\begin{abstract}
The paper utilized vacuum induction melting furnace to smelt three kind of nickel base superalloys as the research subject. It investigated the effect of revert addition on microstructure and mechanical properties of K418 Ni-based superalloy by means of XRD phase test, microstructure observation and tensile test. The original microstructure of material showed dendrite structure, the main phase of $\mathrm{K} 418$ is $\mathrm{Cr}_{1.12} \mathrm{Ni}_{2.88}$, strengthening phases are $\mathrm{Ni}_{3} \mathrm{Al}, \mathrm{Ni}_{0.9} \mathrm{Nb}_{0.1}$ and $\mathrm{Al}_{0.5} \mathrm{Fe}_{0.5}$. The tensile experiment showed when recycled alloy proportion is less than $50 \%$, it had slightly influence on mechanical properties of materials, and it has a good cyclic utilization rate. In view of the high cost of the superalloy, its cyclic utilization is friendly to the environment and it reduces the waste of resource.
\end{abstract}

\section{Introduction}

Nickel base superalloy is one classification of the superalloys that have been developed for elevated temperature services, where relatively severe mechanical stresses are encountered and surface stability is frequently required [1]. Because of its high strength, oxidation resistance, radiation resistance, hot working performance, welding performance, good fatigue properties, fracture toughness and plastic, etc and it contains little scarce resources elements Co, Ni-based superalloy has been widely used in field of the aerospace, power generation, ships, oil and chemical industry [2] [3]. In recent years, facing the bottleneck of $\mathrm{Ni}$, Co resources, the scholars have carried out the research work on recycling of $\mathrm{Ni}$, Co scrap metal complex oxide, waste materials of Ni-base alloy and other secondary resources, in order to resolve the problems of mineral resources bottleneck and the high value of recycling resources [4]. What is more, some literatures showed that the mechanical properties of recycling superalloy are insignificantly influenced by recycled material [5] [6]. Fortunately, these results might indicate that recycled superalloy could also be used in gas turbine engines, and by this way, the efficient recycling of material can be better.

\section{Experiment}

The nickel-base superalloy K418 was investigated in this work, the main raw materials of alloy are electrolytic nickel (99.96\%), metal chromium (99.2\%), pure molybdenum $(99.99 \%)$, aluminum $(99.99 \%)$ and $\mathrm{Nb}-\mathrm{Ni}(67 \%)$, by $50 \mathrm{~kg}$ vacuum induction melting furnace with about $15 \mathrm{~Pa}$ vacuum degree. There is no gas protection in the process of smelting, but it needs to extract gas in all process [7]. Melting temperature of K418 is $1773 \mathrm{~K}$, pouring temperature is $1723 \mathrm{~K}$. Then at the same melting condition, it can be smelt three different superalloys by using K418 revert material feeding head, which can be marked as 10-K418, 30-K418 and 50-K418. Thus, there are three casting rods with $39.5 \mathrm{~mm}$ diameters. The nominal composition of K418 alloy is listed in Table 1 .

The paper investigated the effect of revert addition on microstructure and mechanical properties of K418 Ni-base superalloy by means of XRD phase test, microstructure observation and tensile test. According to the national standard of GB/T 4338-2006, the size of the tensile sample is shown in Fig.1. 
Table 1 Composition of K418 superalloy (wt $\%$ )

\begin{tabular}{|c|c|c|c|c|c|c|c|}
\hline \multirow{4}{*}{ K418 } & $\mathbf{C}$ & $\mathbf{S i}$ & $\mathbf{M n}$ & $\mathbf{P}$ & $\mathbf{S}$ & $\mathbf{N i}$ & $\mathbf{C r}$ \\
\cline { 2 - 8 } & $0.16 / 0.08$ & $\leqq 0.5$ & $\leqq 0.5$ & $\leqq 0.015$ & $\leqq 0.01$ & remain & $13.5 / 11.5$ \\
\cline { 2 - 8 } & $\mathbf{M o}$ & $\mathbf{N b}$ & $\mathbf{T i}$ & $\mathbf{B}$ & $\mathbf{A l}$ & $\mathbf{F e}$ & $\mathbf{Z r}$ \\
\cline { 2 - 8 } & $4.8 / 3.8$ & $2.5 / 1.8$ & $1.0 / 0.5$ & $0.02 / 0.008$ & $6.4 / 5.5$ & $\leqq 1.0$ & $0.15 / 0.06$ \\
\hline
\end{tabular}

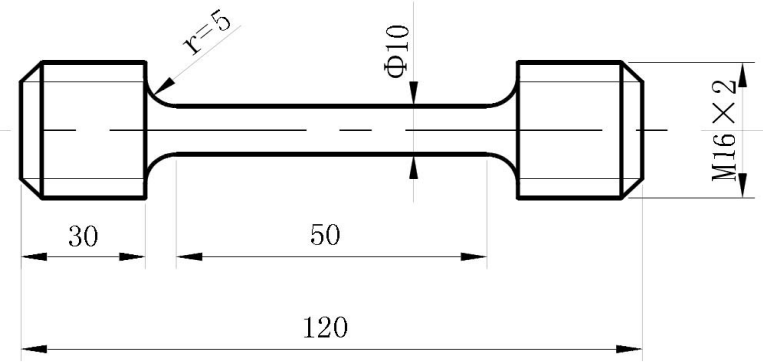

Fig.1. The size of the tensile sample

\section{Results and discussion}

\section{Microstructure and XRD phase test}

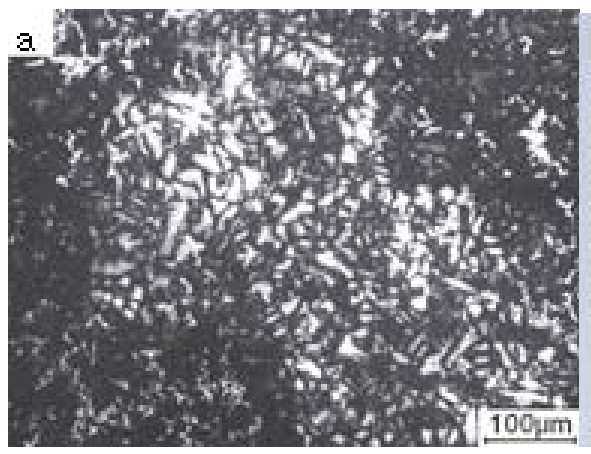

(a) $\mathrm{K} 418$

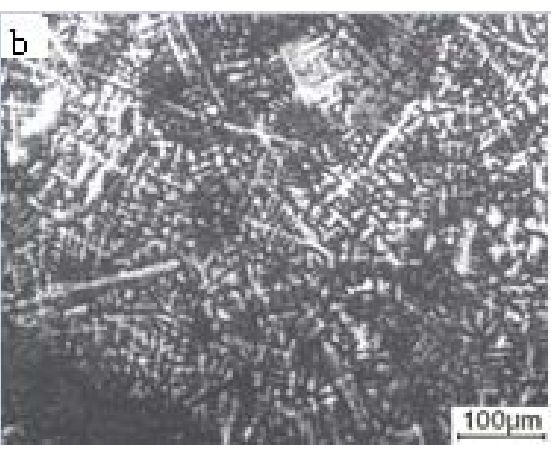

(b) $100-\mathrm{K} 418$

Fig.2. The microstructure of various recycled alloy additions

As is shown in Fig.2, the etchants for superalloy are $20 \mathrm{mlHNO}_{3}$ and $60 \mathrm{mlHCl}$, the microstructure was examined by metalloscope after corrosion of 20 seconds. Fig.2(a) is the metallograph of K418, there are many white reinforcing phases that distribute on K418 substrate. In addition, the scale of white reinforcing phases is relatively large, so the reinforcement is weak. As is known to all, if it is the fine grain, the reinforcement is obvious. Fig.2(b) is the metallograph of $100-\mathrm{K} 418$, as is showed in the picture, the microstructure of $100-\mathrm{K} 418$ is dendritic shape, it can be concluded that the way of solidification is dendritic solidification.

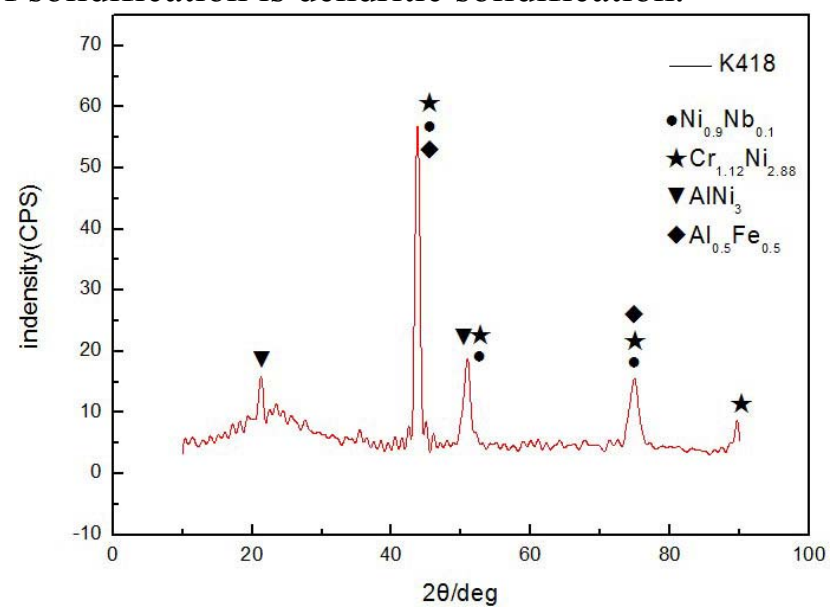

Fig.3. The X-ray diffraction pattern of K418 
Fig.3. is X-ray diffraction pattern of K418 casting superalloy, K418 is Ni-Cr matrix equiaxed casting superalloy, it can be seen that its main phase is $\mathrm{Cr}_{1.12} \mathrm{Ni}_{2.88}$, it is the matrix phase, and $\mathrm{Ni}_{3} \mathrm{Al}$ is its mainly strengthening phase. Besides, it also contains $\mathrm{Ni}_{0.9} \mathrm{Nb}_{0.1}$ that is strengthening phase and little $\mathrm{Al}_{0.5} \mathrm{Fe}_{0.5}$ phase that is strengthened from with $\mathrm{Fe}$ and $\mathrm{Al}$.

\section{Tension test at room temperature}

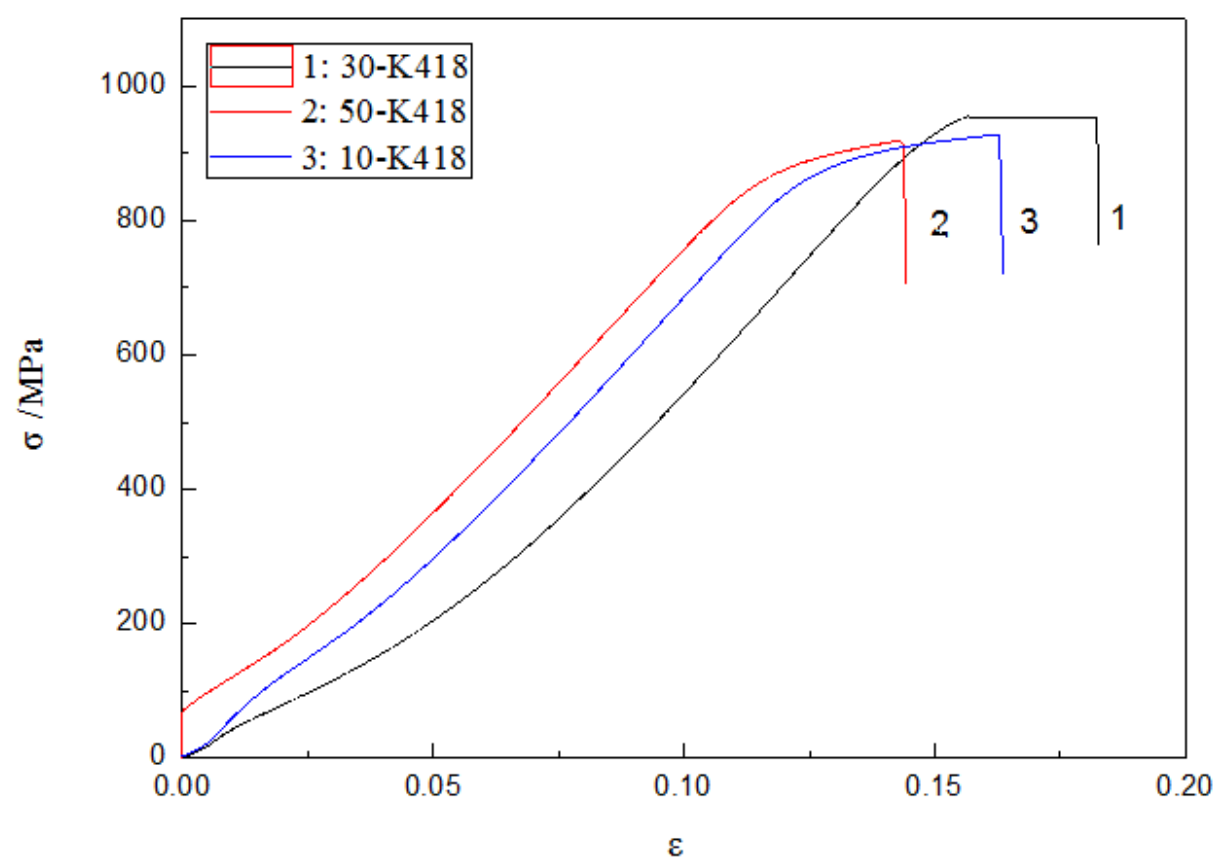

Fig.4. Curve of tensile stress-strain at room temperature

Fig.4. is the curve of tensile stress-strain of three materials at room temperature. As can be seen in the curve of 10-K418 stress-strain, when the value of strain located in 0-0.016, it occurs in elastic deformation. The plastic deformation appears in the strain located in $0.016-0.10$. When the value of stress attains in $927 \mathrm{MPa}$, materials occur fracture and its value of strain attains in 0.16 . The superalloy of 30-K418 occurs in elastic deformation when the value of strain located in $0-0.017$. The plastic deformation appears in the strain located in $0.017-0.157$. When the strain value attains in 0.157 , stress value is $954.4 \mathrm{MPa}$, materials occur fracture. It is shown in the curve of $50-\mathrm{K} 418$ stress-strain, the shape of the curve is similar to $30-\mathrm{K} 418$. When the value of strain located in $0-0.012$, it occurs in elastic deformation. The plastic deformation appears in the strain located in $0.1-0.14$. When the strain value attains in 0.143 , materials occur fracture, the fracture strength value is $908 \mathrm{MPa}$.

It can be concluded that the effect of revert addition on tensile properties of K418 Ni-base superalloy has little influence. In addition, there is not much difference in tensile strength among three kind of materials. 


\section{Tension test at elevated temperature}

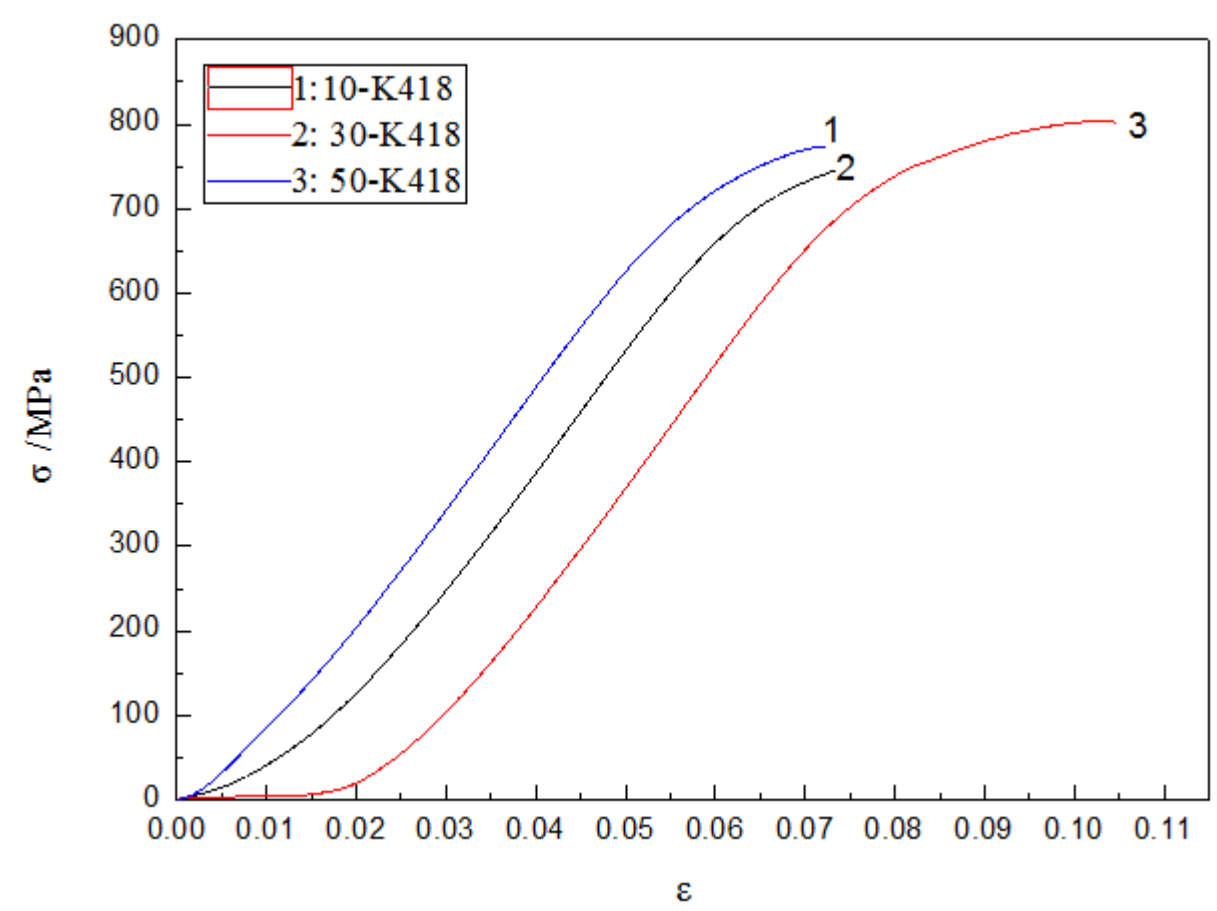

Fig.5. The curve of tensile stress-strain at elevated temperature (1123K)

Fig.5 is the curve of $10-\mathrm{K} 418,30-\mathrm{K} 418$ and $50-\mathrm{K} 418$ tensile stress-strain at $1123 \mathrm{~K}$, it can be seen that stress increases with the increase of strain. When strain is located in $0-0.015$, the $10-\mathrm{K} 418$ occurs in work-hardening, what is more, the effect of work-hardening is more obvious than other two materials. When the strain value attains in 0.07 , stress value is $773 \mathrm{MPa}$, materials occur fracture. As can be seen in the curve of 30-K418 stress-strain, when the value of strain located in $0-0.02$, it occurs in elastic deformation. The plastic deformation appears in the strain located in $0.05-0.07$. When the value of stress attains in $744.5 \mathrm{MPa}$, materials occur fracture and its value of strain attain 0.07 . The shape of the curve of $50-\mathrm{K} 418$ is similar to $30-\mathrm{K} 418$, it occurs in elastic deformation when the value of strain located in 0-0.03, the plastic deformation appears in the strain located in $0.06-0.10$. When the strain value attains at 0.10 , stress value is $802 \mathrm{MPa}$, it occurs in fracture.

It can be concluded that stress increases with the increase of strain, at first, materials occur in elastic deformation within a certain range of strain, then, it enters into plastic deformation, finally, materials occur in fracture. To sum up, the effect of revert addition on elevated temperature tension properties of K418 Ni-base superalloy is little.

\section{Conclusion}

(1) The main phase in the $\mathrm{K} 418$ is $\mathrm{Cr}_{1.12} \mathrm{Ni}_{2.88}$ phase, strengthening phases are $\mathrm{Ni}_{3} \mathrm{Al}$ phase, $\mathrm{Ni}_{0.9}$ $\mathrm{Nb}_{0.1}$ phase and $\mathrm{Al}_{0.5} \mathrm{Fe}_{0.5}$ phase.

(2) By observing original microstructure, it is showed that in K418 superalloy, black phase is matrix phase, it inlaid with white reinforcing phase, and white reinforcing phase has large grain and it is widely distribute in alloy, the strengthening effect of it will become weak to the alloy.

(3) At room temperature, the tensile fracture strength of $10-\mathrm{K} 418,30-\mathrm{K} 418$, and $50-\mathrm{K} 418$ is respectively $927 \mathrm{MPa}, 954.4 \mathrm{MPa}$, and $908 \mathrm{MPa}$. At elevated temperature, the tensile fracture strength of $10-\mathrm{K} 418,30-\mathrm{K} 418$, and $50-\mathrm{K} 418$ is respectively $770 \mathrm{MPa}, 744.5 \mathrm{MPa}$ and $802 \mathrm{MPa}$. It can be concluded that there is little effect of revert addition on mechanical properties of materials. 


\section{Acknowledgement}

Sponsorship of this research by the development plan of national key basic research No.2012CB722800 is gratefully acknowledged.

\section{References}

[1] Metals Handbook, 8th edition, ed. T. Lyman, ASM, Metals Park, 1961:37.

[2] Myer Kutz. Material Select Manual[M]. Chemical Press, 2005, 7.

[3] Changxu Shi and so on. Fifty years of superalloy[M], Metallurgical Industry Press, 2006, 8.

[4] Haiying Wang. The research progress of fatigue property of wrought superalloy Inconel 718 [J]. Shanghai Metals, 2008, 30(1):7-44.

[5] F.W. Chen, X.B. Huang, Mater. Lett. 1998:372-376.

[6] T.L. Wang, J.T. Guo, D.S. Xia, Acta Metall. Sin. 1999:899-902.

[7] Y.H. Yang and so on. Effect of revert addition on microstructure and mechanical properties of M951 Ni-base superalloy [J]. Materials Science and Engineering A, 2012:6-12. 